\title{
Influence of estrogen deficiency and tibolone therapy on trabecular and cortical bone evaluated by computed radiography system in rats ${ }^{1}$
}

\section{Influência da deficiência estrogênica e do tratamento com tibolona no osso trabecular e cortical avaliada pelo sistema de radiografia computadorizada em ratas}

\begin{abstract}
Ana Carolina Bergmann de Carvalho , Gustavo Vieira Oliveira Fernandes ${ }^{\text {II }}$, Inayá Lima ${ }^{\text {III }}$, Davi Ferreira de Oliveira ${ }^{\text {IV }}$, Helene Nara Henriques ', José Augusto Soares Pantaleão ${ }^{\text {, }}$, José Mauro Granjeiro ${ }^{\text {II }}$, Ricardo Tadeu Lopes ${ }^{\text {VI }}$, Maria Angélica GuzmánSilva

IFellow Master degree, Postgraduate Program in Pathology, UFF, Niteroi-RJ, Brazil. Provided guidelines, collection of study informations, manuscript writing.

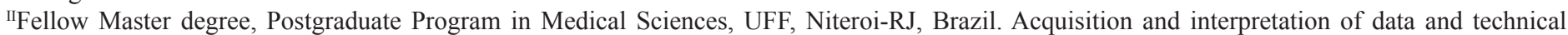
procedures.

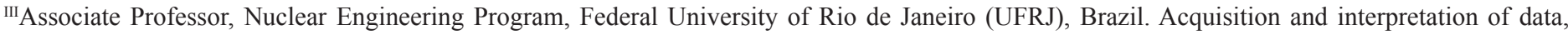
technical procedures.

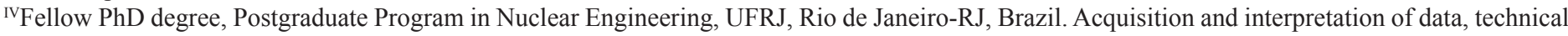
procedures.

${ }^{v}$ Associate Professor, Maternal and Child Department, UFF, Niteroi-RJ, Brazil. Provided guidelines, interpretation of data and technical procedures.

${ }^{\mathrm{VI} A}$ Associate Professor, Department of Cellular and Molecular Biology, UFF, Niteroi-RJ, Senior Researcher, National Institute of Metrology, Quality and Technology, INMETRO, Xerem-RJ, Brazil. Provided guidelines, interpretation of data and technical procedures.

${ }^{\mathrm{VII}}$ Full Professor, Nuclear Engineering Program, UFRJ, Rio de Janeiro-RJ, Brazil. Acquisition and interpretation of data, technical procedures.

${ }^{V}$ Associate Professor, Department of Pathology, UFF, Niteroi-RJ, Brazil. Provided guidelines, conception and design of the study, designed the protocol, manuscript preparation and review.
\end{abstract}

\section{ABSTRACT}

PURPOSE: To verify the effects of tibolone administration on trabecular and cortical bone of ovariectomized female rats by computed radiography system $(\mathrm{CRS})$.

METHODS: The experiment was performed on two groups of rats previously ovariectomized, one received tibolone $(\mathrm{OVX}+\mathrm{T})$ while the other did not (OVX), those groups were compared to a control group (C) not ovariectomized. Tibolone administration (1mg/day) began thirty days after the ovariectomy and the treatment remained for five months. At last, the animals were euthanized and femurs and tibias collected. Computed radiographies of the bones were obtained and the digital images were used to determine the bone optical density and cortical thickness on every group. All results were statistically evaluated with significance set at $P<0.05 \%$.

RESULTS: Tibolone administration was shown to be beneficial only in the densitometric analysis of the femoral head, performing higher optical density compared to OVX. No difference was found in cortical bone thickness.

CONCLUSION: Ovariectomy caused bone loss in the analyzed regions and tibolone administered in high doses over a long period showed not to be fully beneficial, but preserved bone mass in the femoral head.

Key words: Estrogen Replacement Therapy. Steroids. Menopause. Bone. Radiography. Image Interpretation, Computer-Assisted. Rats.

\section{RESUMO}

OBJETIVO: Verificar o efeito da administração de tibolona no tecido ósseo cortical e trabecular de ratas castradas através de radiografia computadorizada.

MÉTODOS: O experimento foi realizado em dois grupos de ratas previamente ooforectomizadas, onde um grupo recebeu tibolona $(\mathrm{OVX}+\mathrm{T})$ e o outro não (OVX). Esses grupos foram comparados a um grupo controle (C) não ooforectomizado. A administração de tibolona $(1 \mathrm{mg} / \mathrm{dia})$ começou trinta dias após a ooforectomia e o tratamento teve duração de cinco meses. No final, os animais foram 
mortos e fêmures e tibias coletados. As radiografias computadorizadas dos ossos foram obtidas e as imagens digitais usadas para determinar a densidade óssea e a espessura cortical em todos os grupos. Todos os resultados foram avaliados estatisticamente com significância estabelecida a 5\%.

RESULTADOS: A administração de tibolona mostrou ser benéfica apenas para análise densitométrica da cabeça do fêmur, apresentando maiores valores de densidade comparada ao grupo OVX. Nenhuma diferença significativa foi encontrada para espessura óssea cortical.

CONCLUSÃO: A ooforectomia ocasionou perda óssea nas regiões analisadas e a tibolona administrada, em dose elevada e durante um longo período, mostrou não ser totalmente benéfica, porém preservou a massa óssea na cabeça femoral.

Descritores: Terapia de Reposição de Estrogênios. Esteróides. Menopausa. Osso. Radiografia. Interpretação de Imagem Assistida por Computador. Ratos.

\section{Introduction}

Research progress and discovery of new treatments in the health field are providing a great increase in women and men's life expectancy, thus increasing the number of people aged over 65 years old, who often have changes from the senescence, such as osteoporosis $^{1}$. This is one of the most common diseases of bone, especially in elderly women, due to estrogen deficiency during the climacteric (postmenopausal period). The disease is characterized by low bone mass and loss of the bone microarchitecture, increasing risk of fractures ${ }^{1,2}$.

Hormone replacement therapy has an established role in preventing postmenopausal osteoporosis and relieving climacteric symptoms. Tibolone was first produced by Organon (West Orange, NJ, USA) as synthetic steroid with estrogenic, androgenic, and progestagenic properties. It has been used primarily for the prevention of postmenopausal osteoporosis and treatment of climacteric symptoms $\mathrm{s}^{3,4}$. Studies using ovariectomized rat model have confirmed that tibolone has a direct estrogenic effect on bone, decreasing bone resorption and maintaining both cortical and trabecular bone quality ${ }^{4,5}$. However, other studies have recommended that special care should be taken in cases of excessive use of this drug compromising the biomechanical competence of bone material ${ }^{6}$.

The incidence of osteoporosis has even increased in the last decades, because of a higher life expectance. As osteoporosis fractures cause significant morbidity, mortality and costs to the public health system, the early detection is very important for establishing effective therapeutic strategies to prevent bone fractures $^{4,7}$.

Radiographs are often the first diagnostic modality that raises suspicion of bone diseases, as osteopenia or even osteoporosis, this last only when bone loss exceeds $30 \%$ to $50 \%{ }^{8}$. Many characteristic sings on radiograms are indicative of "bone loss". The cancellous bone becomes rarefied, resulting in spontaneous fractures ${ }^{7,9}$. Over the last years, in many radiological departments, computed radiography has replaced conventional radiography. The advent of digital imaging in radiology combined with the burst in computer technology has dramatically improved imaging techniques ${ }^{7,9}$. Computed radiography has facilitated operational conveniences, that raise the possibility of a quantitative assessment of bone density, optimizing the diagnostic related to bone $\operatorname{loss}^{7,10}$.

Considering the increase in life expectancy of women, and the constant study of the pathophysiological mechanism of osteoporosis, plus possible therapeutic methods such as administration of tibolone, the development of research related to the issues in question are needed. All these factors attracted us to the interest in studying the use of tibolone inserted in the protocol proposed in this paper, analyzing if the effect of this drug on the bones even with prolonged use and high dosage, would still be beneficial. As reported before, osteoporotic fractures, mainly in climacteric woman, can cause morbidity and mortality. Thus, the early detection of bone loss is essential for the choice of an efficient therapeutic strategy preventing those dreaded fractures. So, the utilization of reliable diagnostic methods for this disease is important due to the incapacities and risks implicated.

In this work, the computed radiography system (CRS) was the chosen method to evaluate the bone optical density in femurs and tibias of previously ovariectomized rats treated with tibolone for a period of five months.

\section{Methods}

The experiment was carried out on 20 mature Wistar rats, eight to 12 weeks old, weighing $240 \mathrm{~g}$ in average. Rats were obtained from the Animal Facility of the Experimental Nutrition Laboratory (LABNE), at the Fluminense Federal University (UFF) in Niteroi (RJ, Brazil). The animals were housed in individual cages, in a temperature controlled $\left(24 \pm 2^{\circ} \mathrm{C}\right)$ facility with 12 -h light-dark 
cycle. Commercial food (FRI-LAB RATOS II, FRI-RIBE) and tap water was supplied ad libitum throughout the experiment. The research was conducted in agreement with the determinations of the Brazilian Society of Animal Science Laboratory (SBCAL/ COBEA) and was approved by the Ethics Committee on Animal Research/Pro-Rector of Research, Postgraduate and Innovation (PROPPi)/UFF.

\section{Experimental design}

Fifteen rats were ovariectomized (OVX) under xylazine $(20 \mathrm{mg} / \mathrm{Kg})$ and ketamine $(100 \mathrm{mg} / \mathrm{Kg})$ anesthesia. The other five rats not ovariectomized composed the control group (C) used only as a parameter of normal bone density. The hormonal treatment began thirty days after the ovariectomy. The rats were randomly distributed into two groups: $\mathrm{OVX}+\mathrm{T}(\mathrm{n}=9)$ and OVX $(n=6)$ and the treatment was performed for five months. Every day $1 \mathrm{mg}$ of tibolone was administered per os in the vehicle $(0.5 \%$ carboxymethylcellulose solution) in a volume of $0.5 \mathrm{ml}$. Only the vehicle solution was administered to the OVX group. After the treatment, $\mathrm{OVX}+\mathrm{T}, \mathrm{OVX}$ and $\mathrm{C}$ rats were killed by spinal cord dislocation after anesthesia as described above. Left tibias and femurs were isolated and the computed radiography process was performed after freeing the bones from muscular tissue.

\section{Computed radiography}

Computed radiographies of the bones were obtained at the Nuclear Instrumentation Laboratory (UFRJ), using CR 50P Portable Computed Radiography Scanner (GE system), imaging plate IPX and an X-Ray micro focus tube (Fein focus system). Some experimental parameters were selected and standardized, operating with $40 \mathrm{kVp}, 125 \mathrm{~mA}$, source-detector distance of 1500 $\mathrm{mm}$, source-object distance of $300 \mathrm{~mm}$, exposure time of $600 \mathrm{~s}$ and magnification factor 5; the pixel size of the image was $50 \mu \mathrm{m}$.

Digital images were used to determine the bone optical density and the cortical thickness in the left femur and tibia in all groups. Regions of Interest (ROIs) - femoral neck, femoral and tibial diaphysis and distal tibia - were chosen to measure the cortical thickness. Measurements were performed using the Image J software (Figure 1). The same software was used to determine the bone optical density of four other ROIs - femoral head, femoral neck, femoral condyle, and proximal tibia (Figure 2 ). The bone optical density is based on the gray values of the radiographic image, so higher gray values in the scale represent less bone density. To this last analysis, which was performed to quantify the gray scale, we standardized a square of fixed size (598 x 614 pixels), which was positioned in the ROIs described above. Next, we used the tool Analyze - Plot profile of the Image $\mathrm{J}$ software, which provided a curve shape varied depending on the shades of gray belonging to the selected region. The values obtained were converted to a profile and the area under the curve was calculated being considered as the optical density of that region. This calculation was made using the software GraphPad PRISM 5 for Windows. The standardization of parameters is necessary to minimize the occurrence of variables that can affect the outcome of final radiographic image, considering that, the squares of fixed size as described above were positioned with the cursor, in the same positions for all analysis, always comprising only the trabecular area of the selected ROIs.
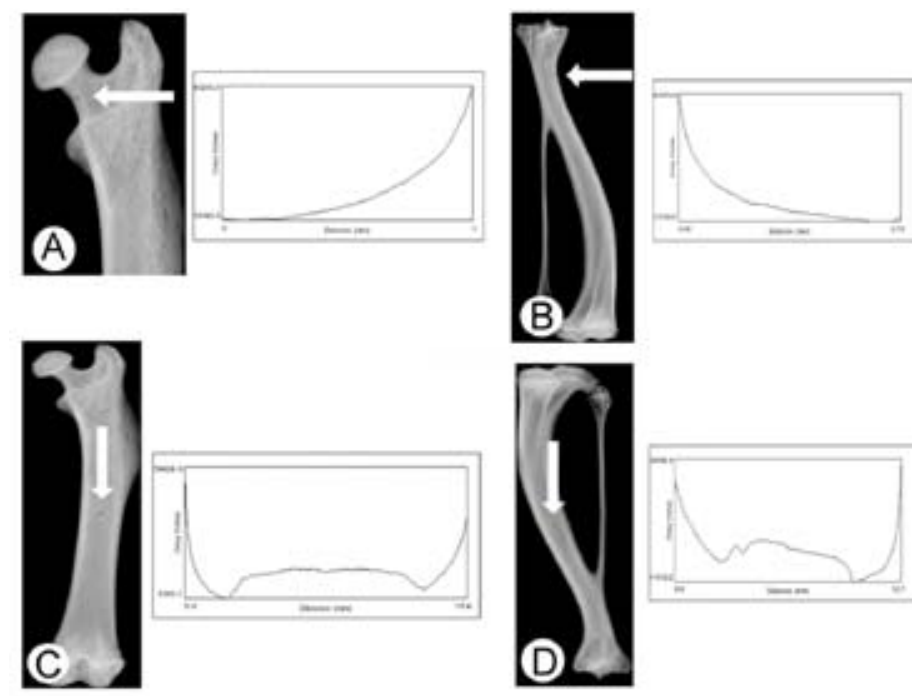

FIGURE 1 - Measurements of cortical thickness in standardized locations through the tool Straight Line Selections (Image J software). The cortical thickness is shown using the tool Analyze - Plot profile where the $\mathrm{X}$ axis gives the value in millimeters: (A) Middle of the cortical femoral neck, (B) Distal tibia, (C) Femoral diaphysis and (D) Tibial diaphysis.
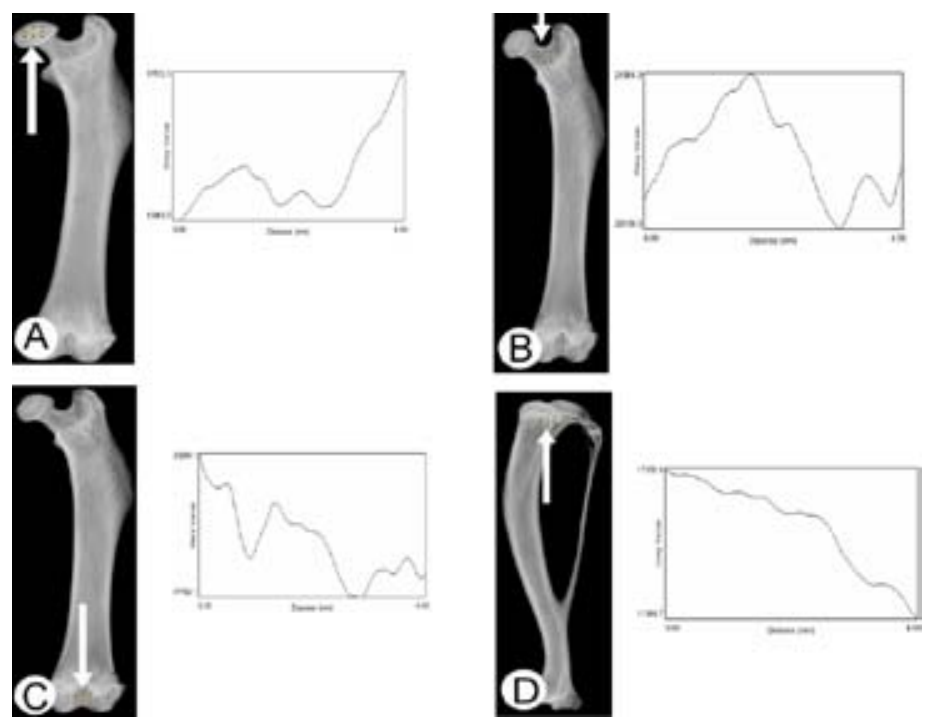

FIGURE 2 - Measurements of optical density in standardized locations where a square identical in size was drawn using the tool Rectangular Selections (Image J software) and the tool Analyze - Plot profile gives the gray value for each pixel in the square analyzed: (A) Femoral head, (B) Femoral neck, (C) Femoral condyle and (D) Proximal tibia. 


\section{Statistical analysis}

Results were expressed as mean \pm standard error (SEM). The results of only two groups showing normality in their distribution were compared by Student $t$ test. The analysis of variance (ANOVA) and post-hoc test of Bonferroni were applied to compare the results that followed the normal distribution and involved all three groups; otherwise Kruskal-Wallis and Dunn's test as post hoc were performed. All tests were applied with significance set at 5\% and statistical analysis was processed by the program GraphPad Prism 5 for Windows.

\section{Results}

\section{Cortical bone thickness}

Cortical bone thickness in the femoral neck and distal tibia showed no significant differences among groups (Figures $3 \mathrm{~A}$ and $3 \mathrm{~B})$. Femoral and tibial diaphysis cortical thickness was greater in control group than in $\mathrm{OVX}+\mathrm{T}$ group $(P<0.05)$, but no significant difference was found between $\mathrm{OVX}+\mathrm{T}$ and OVX group (Figures 3C and 3D).
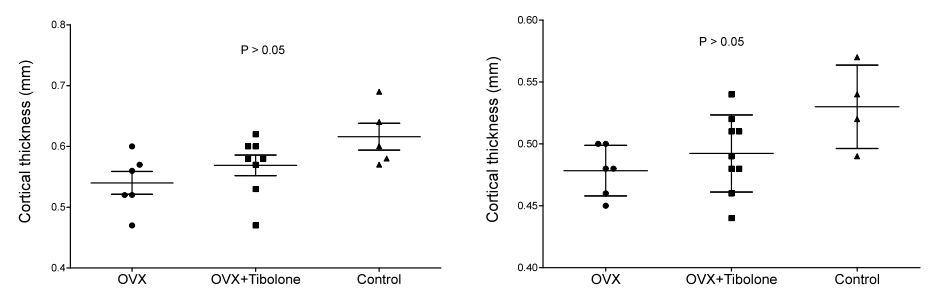

A
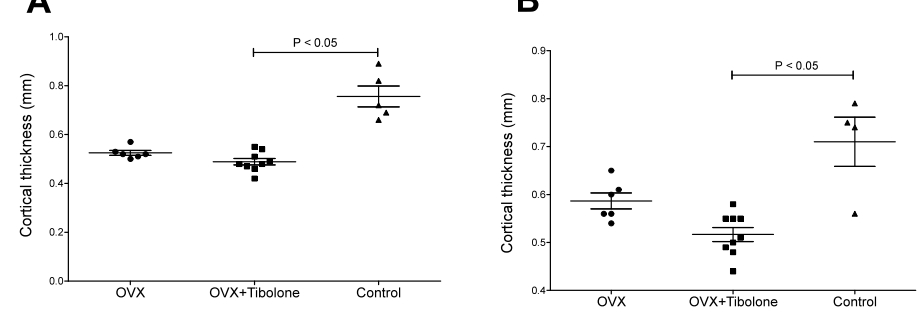

C

\section{D}

FIGURE 3 - Analyses of cortical thickness: (A) Femoral neck, (B) Distal tibia, (C) Femoral diaphysis and (D) Tibial diaphysis.

\section{Bone density}

Tibolone treatment (OVX+T group) significantly increased the bone optical density, showing lower values in shades of gray in relation to OVX group at the femoral head (Figure 4A), but did not at femoral neck as shows Figure $4 \mathrm{~b}$. Both groups presented higher values $(P<0.05)$ in shades of gray than control group (Figures 4A and 4B). No significant changes in bone density occurred in the femoral condyle and proximal tibia for all groups (Figures 4C and 4D).
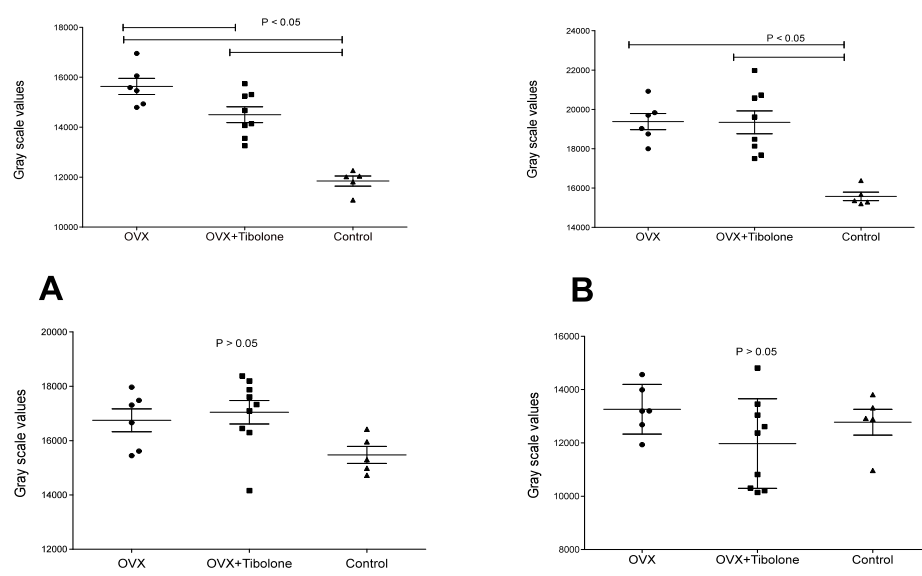

B

\section{C}

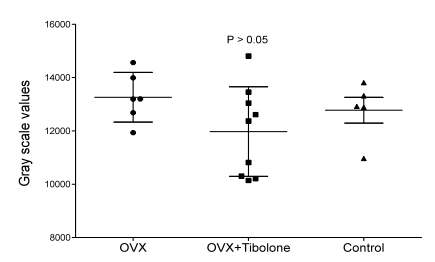

FIGURE 4 - Analyses of bone optical density: (A) Femoral head, (B) Femoral neck, (C) Femoral condyle and (D) Proximal tibia.

\section{Discussion}

It is well known that the synthetic steroid tibolone preserves bone mass similar to estrogen through inhibition of increased bone resorption induced by ovariectomy. However, despite being a drug indicated for the treatment of menopause symptoms and osteoporosis prevention with proven effectiveness, attention should be paid to possible inappropriate administration, because if the reduction in bone remodeling is excessive, it may compromise the biomechanical competence of bone material in long term treatment ${ }^{7}$. This possible adverse effects, awakened our interest to study the use of tibolone under the protocol proposed in this work, on the effect that this drug has on the bones being still beneficial, even with prolonged use in high dosage. The CRS was the method chosen to evaluate the bone optical density in femurs and tibias as well as cortical thickness.

Compared with the human body, the metabolism of rats is greatly accelerated. The life expectancy of most strains is about two and a half to three years ${ }^{11}$. Studies show that these animals, with 24 months of life, roughly corresponding to an individual of 60 years. This means that every day life of the animal correspond to approximately 30 days in humans ${ }^{12,13}$. The current experiment lasted 5 months, which, if extrapolated to the corresponding lifetime in women, mean roughly 11.5 years.

Most studies in humans use a dose of $2.5 \mathrm{mg}^{14-16}$, which corresponds to $0.041 \mathrm{mg} / \mathrm{kg}$ in a $60 \mathrm{~kg}$ woman. Some studies even recommend that a lower dose of $1.25 \mathrm{mg}$ of tibolone would have the same beneficial effects in bone ${ }^{14,17}$ or would be even better ${ }^{18}$. The dose of tibolone used in the current experiment was considered high compared to the commonly used in humans. Through allometric calculation ${ }^{19}$, it was found that the dose used 
in this study, $1 \mathrm{mg} /$ day per animal represent a dose 24 times higher than the usual in humans.

Elderly women are at higher risk for hip fracture because of additional and relatively rapid bone loss due to estrogen deficiency by loss of the ovarian function and a longer average life span than men ${ }^{6,20}$. As in humans, ovarian hormone deficiency in rats also accelerates bone remodeling. Both (rats and humans) exhibit similar changes in bone mass and structure at numerous skeletal locations following loss of estrogen ${ }^{2,4,20}$. Estrogen deficiency in humans causes both trabecular bone loss and architectural deterioration, giving rise of an increased incidence of osteoporotic fracture ${ }^{4,20,21}$. Several studies have demonstrated that estrogen replacement therapy can effectively prevent trabecular as well as cortical bone loss by reducing bone resorption, showing to reduce the risk of skeletal fractures ${ }^{4,20,22}$. The present study confirms the estrogenic effect of tibolone at the femoral head reducing the bone resorption, since an increased bone density was found when compared to the OVX group. Tibolone preserves bone mass like estrogens through an inhibition of ovariectomy-increased bone resorption ${ }^{7}$

Studies indicate that the effects of ovariectomy may happen in a month or even less with bone loss characteristics very similar to old rats $^{3}$. In our results, the femoral head of the OVX group showed significantly lower bone density compared to $\mathrm{C}$ group, so a probable bone loss happened in those regions due to OVX. These data are in agreement with a previous research through dual-energy X-ray absorptiometry (DXA), which found a significantly lower bone mineral density (BMD) in the proximal and distal femur regions of the ovariectomized group ${ }^{23}$. Previous study found that ovariectomy caused a significant decrease - 51\% - of trabecular BMD, in the distal femur of OVX rats, compared to the sham group ${ }^{24}$. In our study, contrasting to the above, the density of the distal femur (femoral condyle) was analyzed by the gray level on CRS and there was no statistical difference between the groups.

The distal and proximal femoral regions contain both cortical and trabecular bone, being exquisitely sensitive to estrogen deprivation and many studies have reported that ovariectomy results in a rapid and profound osteopenia in these locations. Previous reports have described the need to study both cancellous and cortical bone loss for screening of therapeutic agents in osteoporosis $^{20}$. This prompted us to choose the femoral and tibial proximal and distal regions as ROIs for studying the cortical and trabecular bone resorption using the CRS.

The purpose of this study was to quantify cortical and cancellous bone changes induced by tibolone in OVX rats using the CRS and compared these results with those obtained in OVX and non-ovariectomized rats. No significant effect was found at skeletal sites dominated by cortical bone, including femoral neck, distal tibia and the diaphysis of both bones, being in accordance with previous observations ${ }^{21,24}$. Moreover, trabecular bone is much more responsive to hormonal as well as pharmacological intervention than cortical bone ${ }^{22}$. In our findings, only one ROI femoral head in rats treated with tibolone - showed a significant increase in bone density, indicating less bone loss; no significant difference was found between the groups in the other locations analyzed.

CRS is generally the first choice of diagnostic method to study bone diseases, since it is simpler, less expensive, and easier to use $\mathrm{e}^{25}$. Tibolone is effective showing beneficial estrogen action in tissues such as vagina, vascular system and even the bone $e^{5,17}$. However, in the latter tissue, the administration of this drug for a long time and in higher dose did not improve the quality of cortical and trabecular bone in the regions analyzed. It's important to emphasize that despite this, tibolone was not harmful to the bone mass, since compared with the OVX group, the OVX + T showed similar histomorphometric parameters analyzed.

Thus, with the information obtained, one can raise a scientific question about the biological behavior of models studying drug's effect. If the drug is administered in excessive dosage or time, could cause bone changes that are unfavorable to the primary goal of therapy. However, we must be cautious in extrapolating these results to humans, so more research is needed about the issue. The new approach in this protocol and our results warn that care must be taken with new protocols with hormone replacement, especially considering that currently, women end up spending longer time using hormones due to a more prolonged period of post-menopause, always bearing in mind better quality of life.

\section{Conclusions}

Ovariectomy caused bone loss in the analyzed regions and tibolone administered in high dose showed not to be fully beneficial, but preserved bone mass in the femoral head. Finally, computed radiography system is an efficient method to identify bone loss process, and to evaluate potential therapies, as tibolone administration.

\section{References}

1. De Lorenzi DRS, Baracat EC, Saciloto B, Padilha Jr I. Factors related to quality of life in post-menopause. Rev Assoc Med Bras. 
2006;52(5):312-7.

2. Comelekoglu U, Bagis S, Yalin S, Ogenler O, Yildiz A, Sahin NO, Oguz I, Hatungil R. Biomechanical evaluation in osteoporosis: ovariectomized rat model. Clin Rheumatol. 2007;26:380-4.

3. Pytlik M. Effects of tibolone on the development of osteopenia induced by ovariectomy in rats. Pol J Pharmacol. 2002;54:35-43.

4. Damilakis J, Maris TG, Karantanas AH. An update on the assessment of osteoporosis using radiological techniques. Eur Radiol. 2007;17:1591-602.

5. Palacios S. Tibolone: what does tissue specific mean? Maturitas. 2001;37:159-65

6. Ederveen AGH, Spanjers CPM, Quaijtaal JHM, Kloosterboer HJ Effects of 16 months of treatment with tibolone on bone mass, turnover, and biomechanical quality in mature ovariectomized rats. J Bone Miner Res. 2001;16(9):1674-81.

7. Wagner S, Stäbler A, Sittek H, Bonel H, Laeverenz G, Reiser MF, Baur-Melnyk A. Diagnosis of osteoporosis: visual assessment on conventional versus digital radiographs. Osteoporos Int. 2005; 16:1815-22.

8. Sah AP, Thornhill TS, Leboff MS, Glowacki J. Correlation of plane radiographic indices of the hip with quantitative bone mineral density. Osteoporos Int. 2007;18:1119-26.

9. Busch HP, Faulkner K. Image quality and dose management in digital radiography: a new paradigm of optimization. Radiat Prot Dosimetry. 2005;117(1-3):143-7.

10. Samei E, Dobbins III JT, Lo JY, Tornai MP. A framework for optimizing the radiographic technique in digital x-ray imaging. Radiat Prot Dosimetry. 2005;114(1-3):220-9.

11. Canadian Council on Animal Care. Guide to the Care and Use of Experimental Animals. Ottawa, CCAC. 1984;1:298.

12. Campbell SJ, Carare-Nnadit RO, Losey PH, Anthony DC. Loss of the atypical inflammatory response in juvenile and aged rats. Neuropathol Appl Neurobiol. 2007;33(1):108-20.

13. Kang KB, Zypp AVD, Iannazzo L, Majewski H. Age-related changes in monocyte and platelet cyclooxygenase expression in healthy male humans and rats. Transl Res. 2006;148(6):289-94.

14. Ettinger B. Tibolone for prevention and treatment of postmenopausal osteoporosis. Maturitas. 2007;57:35-8.

15. Prelevic GM, Markou A, Arnold A, Bartram C, Puzigaca C, Ginsburg J. The effect of tibolone on bone mineral density in postmenopausal women with osteopenia or osteoporosis -8 years follow-up. Maturitas. 2004;47:229-34.

16. Rymer J, Robinson J, Fogelman I. Effects of 8 years of treatment with tibolone $2.5 \mathrm{mg}$ daily on postmenopausal bone loss. Osteoporosis Int. 2001;12:478-83.

17. Kenemans P. Tibolone: how does its mechanism of action translate into clinical effects. Maturitas. 2004;48:S1-3.

18. Delmas PD, Davis SR, Hensen J, Adami S. Effects of tibolone and raloxifene on bone mineral density in osteopenic postmenopausal women. Osteoporos Int. 2008;19(8):1153-60.

19. Felippe PAN. Sistema alométrico ou cálculo de dosagem por taxa metabólica do animal. Disponível em: http://www.ib.unicamp.br/ ceea/files/ceea/calculo.doc. Acesso em: 20 ago. 2008.

20. Bagi CM, Ammann P, Rizzoli R, Miller SC. Effect of estrogen deficiency on cancellous and cortical bone structure and strength of the femoral neck in rats. Calcif Tissue Int. 1997;61:336-44.

21. Mosekilde L, Thomsen JS, Orhii PB, Kalu DN. Growth hormone increases vertebral and femoral bone strength in osteopenic, ovariectomized, aged rats in a dose-dependent and site-specific manner. Bone. 1998;23(4):343-52.

22. Berning B, Kuijk CV, Kuiper JW, Coelingh Bennink HJT, Kicovic PM, Fauser BCJM. Effects of two doses of tibolone on trabecular and cortical bone loss in early postmenopausal women: a two-year randomized, placebo-conteolled study. Bone. 1996;19(4):395-9.

23. Yoshitake K, Yokota K, Kasugai Y, Kagawa M, Sukamoto T, Nakamura, T. Effects of 16 weeks of treatment with tibolone on bone mass and bone mechanical and histomorphometric indices in mature ovariectomized rats with established osteopenia on a lowcalcium diet. Bone. 1999;25(3):311-9.

24. Ederveen AG, Kloosterboer HJ. Tibolone, a steroid with a tissuespecific hormonal profile, completely prevents ovariectomyinduced bone loss in sexually mature rats. J Bone Miner Res. 1999;14(11):1963-70.

25. Link TM, Guglielmi G, Kuijk CV, Adams JE. Radiologic assessment of osteoporotic vertebral fractures: diagnostic and prognostic implications. Eur Radiol. 2005;15:1521-32.

\section{Acknowledgments}

This work was partially supported by CNPq (National Council for Scientific and Technological Development), FAPERJ (Rio de Janeiro Research Foundation), CAPES (Co-ordination of Improvement for High Academic Staff), PIBIC/UFF (Institutional Program on Scientific Initiation Scholarship), PROPPi/UFF (Pro-rectory Research, Postgraduation and Inovation) and FINEP (Financial Studies and Projects). The authors are grateful to OFFICILAB for the donation of tibolone.

\section{Correspondence:}

Ana Carolina Bergmann de Carvalho

Avenida Rui Barbosa, 197/302 Bloco 02

24360-440 Niterói - RJ Brasil

carolberg12@hotmail.com

Tel.: (55 21)8122-7360

Received: October 11, 2011

Review: December 07, 2011

Accepted: January 10, 2012

Conflict of interest: none

Financial sources: FAPERJ, PROPPi/UFF, FINEP

${ }^{1}$ Research performed at Department of Pathology, Fluminense Federal University (UFF), Niteroi-RJ, Brazil. Part of Master's thesis. Tutor: Maria Angélica Guzmán-Silva. 